\title{
LIKELIHOOD ESTIMATION OF THE TIME OF ORIGIN OF WHALES (CETACEA)
}

GINGERICH, Philip D., Museum of Paleontology and Department of Geological Sciences, The University of Michigan, Ann Arbor, MI 48109-1079, U.S.A.; UHEN, Mark D., Museum of Paleontology and Department of Geological Sciences, The University of Michigan, Ann Arbor, MI 48109-1079, U.S.A.

Archaeocete cetaceans are known from many fossil localities in Eocene marginal and shallow marine strata on six continents. Archaeocetes include transitional amphibious forms, and constitute the first major radiation of whales. Mysticeti and Odontoceti evolved from Archaeoceti, and the origin of archaeocetes thus marks the time of origin of Cetacea. Of all of the localities yielding archaeocetes, approximately 46 can be considered independent records.

Discoveries are considered to be independent if they are in different geological formations within a state, or from the same formation in a different state, province, or country. These records range from late Ypresian (late early Eocene; ca. 49.5 Ma) through Priabonian (late Eocene; ca. $36 \mathrm{Ma}$ ) in age, a $13.5 \mathrm{~m} . \mathrm{y}$. time range, and they are widely distributed in North America (18 sites), Europe (5 sites), Asia (10 sites), Africa (10 sites), Australia (New Zealand; 2 sites), and Antarctica (1 site).

Given this information, we can calculate a likelihood distribution that archaeocetes originated and can be found as fossils at different hypothesized times before the oldest discovery known to date. This is a one-tailed problem because we are estimating the likelihoods of different hypothesized times of origination only. Quantification is necessarily based on some model of the distribution of potential fossils in the stratigraphic record, and we use a model (see figure) that is (1) exponentially increasing in the time or $t$-direction-to represent increasing subaerial exposure of later geological strata, and (2) uniformly increasing in the diversity or $d$-direction from the 95\% origination limit to the time the fossil record begins-to represent increasing numbers and diversity during adaptive radiation. Each likelihood is the probability of sampling a fossil record larger by some size and finding that all independent records fall, by chance, in the known archaeocete stratigraphic range. The minimum acceptable likelihood, here 0.05 , tested by simulation, corresponds to a $1-0.05=95 \%$ confidence limit. Discovery of older fossils is generally less likely than discovery of younger fossils, for exposure and diversity reasons, and our calculation is substantially more conservative (extending the hypothesized range farther back in time) than calculations based on uniform distributions of fossils. Our $95 \%$ confidence limit for the time of origin of whales is about 51.4 million years before present, well within the early Eocene. Archaeocetes are not likely to be found in Paleocene or earlier strata.

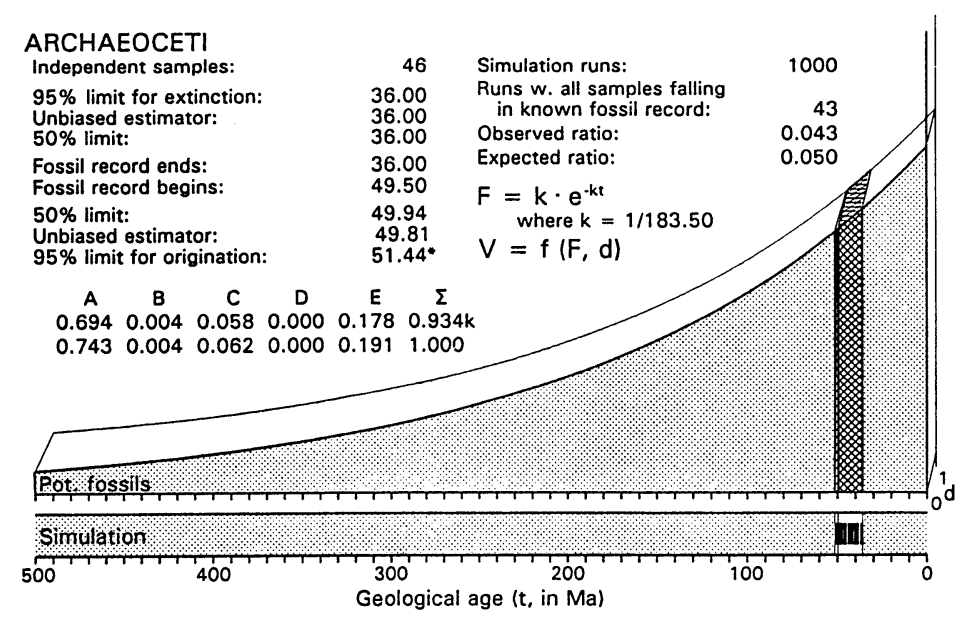

